\title{
Anti-inflammatory effects of miR-150 are associated with the downregulation of STAT1 in macrophages following lipopolysaccharide treatment
}

\author{
SONG CHEN, HAIJUN ZHU, JIE SUN, LILI ZHU, LONG QIN and JIAN WAN \\ Department of Emergency and Critical Care Medicine, The People's Hospital of Pudong New Area, \\ Shanghai University of Health and Science, Shanghai 201200, P.R. China
}

Received August 1, 2019; Accepted March 3, 2020

DOI: $10.3892 /$ etm.2021.10483

\begin{abstract}
Sepsis is a condition that is associated with high rates of mortality. It is characterized by serious systemic inflammatory responses induced by pathogenic invasion. Although microRNA-150 (miR-150) has been previously reported to be involved in the modulation of sepsis, the underlying molecular mechanism in sepsis remains poorly understood. In the present study, the human monocytic cell line THP-1 was treated with LPS to mimic sepsis in vitro, following which miR-150 and STAT1 expression were measured using reverse transcription-quantitative PCR or western blotting. Secretion of inflammatory cytokines interleukin (IL)-1 $\beta$, IL-6 and tumor necrosis factor- $\alpha$ (TNF- $\alpha$ ) into the medium were measured by ELISA. The potential relationship between STAT1 and miR-150 was determined using dual-luciferase reporter and RNA immunoprecipitation assays. miR-150 expression was found to be was downregulated by LPS treatment in THP-1 cells in both dose- and time-dependent manners. LPS treatment also induced IL-1 $\beta$, IL- 6 and TNF- $\alpha$ secretion in a manner that could be inhibited by miR-150 overexpression and enhanced by transfection with the miR-150 inhibitor. miR-150 was revealed to directly target STAT1 by negatively regulating its expression. In addition, STAT1 expression was demonstrated to be upregulated by LPS treatment. STAT1 overexpression reversed the inhibitory effects of miR-150 overexpression on IL-1 $\beta$, IL- 6 and TNF- $\alpha$ secretion whilst STAT1 knockdown attenuated IL-1 $\beta$, IL- 6 and TNF- $\alpha$ secretion induced by miR-150 inhibitor transfection. In conclusion, the present study suggested that miR-150 regulates the inflammatory response in macrophages following LPS challenge by regulating the expression of STAT1.
\end{abstract}

Correspondence to: Dr Jian Wan, Department of Emergency and Critical Care Medicine, The People's Hospital of Pudong New Area, Shanghai University of Health and Science, 490 South Chuanhuan Road, Shanghai 201200, P.R. China

E-mail: drjian@yeah.net

Key words: sepsis, lipopolysaccharide, microRNA-150, STAT1

\section{Introduction}

Sepsis is a systemic inflammatory response syndrome that is caused by pathogenic infection (1). Sepsis is one of the leading causes of mortality in patients in intensive care units, with a rate of 30-50\% worldwide (2). Pathogenic invasion triggers the release of substantial amounts of inflammatory factors that results in a systemic inflammatory response $(3,4)$. In particular, macrophages have been previously reported to serve as a cell type of the innate immune response that is indispensable for the process of sepsis (5).

Lipopolysaccharide (LPS) is a major component of the outer membrane of pathogenic Gram-negative bacteria that can induce cytotoxicity by activating the innate immune system, leading to the production of inflammatory mediators associated with septic shock (6-8). LPS is recognized by toll-like receptor 4 on macrophages which induces the triggering of downstream signaling cascades and the production of cytokines, including tumor necrosis factor (TNF)- $\beta$ and interleukin (IL)-10 $(9,10)$. These cytokines in turn bind to their respective receptors and promote the constitutive activation of the Janus kinase (JAK)/STAT pathway during inflammation and sepsis $(11,12)$. However, the detailed mechanism underlying inflammation following LPS exposure remain to be fully elucidated.

MicroRNAs (miRNA or miR) are noncoding, single-stranded RNA molecules that participate in the regulation of gene expression by reducing mRNA stability and inhibiting mRNA translation (13). miRNAs serve as key regulators in a variety of biological processes, including development, differentiation, homeostasis and elements during immune responses $(14,15)$. Although previous studies have demonstrated associations of a large number of miRNAs with the inflammatory response mediated by macrophages, including miR-709 (16), miR-1224 (17), miR-203 (18), miR-125b (19) and miR-149 (20), functional studies in the potential relationship between miR-150 and LPS challenge in macrophages remain insufficient.

In the present study, an LPS-treated macrophage cell line THP-1 was used to mimic sepsis in vitro, where the relationship between miR-150 and the secretion of inflammatory cytokines IL-1 $\beta$, IL- 6 and TNF- $\alpha$ in LPS-treated THP-1 cells was 
subsequently examined. Dual-luciferase assays revealed that miR-150 could regulate STAT1 expression by direct binding, whilst functional studies demonstrated that miR-150/STAT1 was involved in the sepsis progression in vitro.

\section{Materials and methods}

Cell culture. Human monocytic cell line THP-1 was purchased from American Type Culture Collection. The cells were maintained in DMEM (Invitrogen; Thermo Fisher Scientific, Inc.) supplemented with 10\% FBS (Invitrogen; Thermo Fisher Scientific, Inc.) in a humidified incubator under $37^{\circ} \mathrm{C}$ and $5 \% \mathrm{CO}_{2}$.

To establish the sepsis model in vitro, THP-1 cells were treated with LPS (Sigma-Aldrich; Merck KGaA) at concentrations of $0,0.5,1$ or $2 \mu \mathrm{g} / \mathrm{ml}$ for $0,12,24$ or $48 \mathrm{~h}$ at $37^{\circ} \mathrm{C}$. The untreated THP-1 cells were considered as the control. In transfected cells, after $24 \mathrm{~h}, 1 \mu \mathrm{g} / \mathrm{ml}$ LPS were used to treat the cells for another $24 \mathrm{~h}$, following which the levels of cytokines in the medium were measured by ELISA.

$R N A$ isolation and reverse transcription-quantitative PCR $(R T-q P C R)$. Total mRNA was isolated using an RNAiso Plus kit (cat. no. 9109; Takara Bio, Inc.) according to manufacturer's protocol. In total, $5 \mu \mathrm{g}$ RNA was used to synthesize cDNA using the PrimeScript ${ }^{\mathrm{TM}} \mathrm{RT}$ reagent kit according to manufacturer's protocol (Takara Bio, Inc.). Briefly, the transcription was conducted in a $10 \mu \mathrm{l}$ reaction mixture, including polyadenylated RNA (100 ng), $5 \mathrm{X}$ PrimeScript buffer $(2 \mu 1)$, PrimeScript RT Enzyme Mix I $(0.5 \mu 1)$, RT primer mixure (1 $\mu \mathrm{l})$ and RNase-free water. Then, total reaction mixture was incubated at $50^{\circ} \mathrm{C}$ for $15 \mathrm{~min}$ and $85^{\circ} \mathrm{C}$ for $5 \mathrm{sec}$. qPCR was performed using $\mathrm{SYBR}^{\circledR}$ Premix Ex Taq $^{\mathrm{TM}}$ kit (Takara Bio, Inc.) in $15 \mu \mathrm{l}$ final volume containing $1.5 \mu \mathrm{l}$ template cDNA mixed with $7.5 \mu 12 \mathrm{X}$ SYBR Green PCR master mix and $3 \mu 1$ of each forward and reverse primers. The amplification parameters were as follows: Denaturation at $95^{\circ} \mathrm{C}$ for $10 \mathrm{~min}$, followed by 40 cycles of denaturation at $95^{\circ} \mathrm{C}$ for $30 \mathrm{sec}$, annealing at $60^{\circ} \mathrm{C}$ for $30 \mathrm{sec}$ and extension at $72^{\circ} \mathrm{C}$ for $1 \mathrm{~min}$.

miRNA was isolated from cells using the miRCURY ${ }^{\mathrm{TM}}$ RNA Isolation kit (cat. no. 300110; Exiqon; Qiagen China Co., Ltd.) according to the manufacturer's protocols, which was reverse transcribed in cDNA using Reverse Transcriptase M-MLV (RNase H; cat. no. 2641A; Takara Bio, Inc.). First, $5 \mu 1$ of RNA, $2 \mu 1 \mathrm{miR} 39$-specific primer $(10 \mu \mathrm{M}), 2 \mu 1$ miR150-specific primer $(10 \mu \mathrm{M})$ and $1 \mu \mathrm{l}$ of $10 \mathrm{mM} \mathrm{dNTP} \mathrm{mix}$, were heated to $65^{\circ} \mathrm{C}$ for $5 \mathrm{~min}$ and incubated on ice for $2 \mathrm{~min}$. Next, $2 \mu \mathrm{l}$ 10X first-strand buffer, $4 \mu 125 \mathrm{mM} \mathrm{MgCl}_{2}, 2 \mu \mathrm{l}$ 0.1 M DTT, $1 \mu 1$ RNaseOUT $^{\text {TM }}$ Recombinant RNase Inhibitor, and $1 \mu 1$ of SuperScript ${ }^{\mathrm{TM}}$ III RT $(200 \mathrm{U} / \mu \mathrm{l})$ are added to the mixture. The $10 \mu \mathrm{l}$ mixtures were incubated in a thermocycler for $30 \mathrm{~min}$ at $16^{\circ} \mathrm{C}, 30^{\circ} \mathrm{C}$ for $30 \mathrm{sec}, 42^{\circ} \mathrm{C}$ for $30 \mathrm{sec}$, and $50^{\circ} \mathrm{C}$ for $1 \mathrm{sec}$ and finally heated at $70^{\circ} \mathrm{C}$ for $15 \mathrm{~min}$. The $20 \mu \mathrm{l}$ PCR included 2.0 $\mu \mathrm{l}$ RT product, 1X Premix ExTaq buffer for qPCR, $0.2 \mu \mathrm{M}$ TaqMan probe, $0.02 \mu \mathrm{M}$ forward primer 1, $0.6 \mu \mathrm{M}$ forward primer 2 and $0.4 \mu \mathrm{M}$ reverse primer. The reaction mixtures were incubated in a 96 -well plate at $95^{\circ} \mathrm{C}$ for $30 \mathrm{sec}$, followed by 55 cycles of $95^{\circ} \mathrm{C}$ for $15 \mathrm{sec}$ and $60^{\circ} \mathrm{C}$ for $30 \mathrm{sec}$.
Quantity and quality of the RNA obtained were determined using a Quant-iT ${ }^{\mathrm{TM}}$ RNA Assay kit according to manufacturer's protocol (Invitrogen; Thermo Fisher Scientific, Inc.). U6 was used as the reference gene for miR-150 expression whilst $\beta$-actin was used as the reference gene for STAT1 mRNA expression. Relative quantification of target genes was performed using the $2^{-\Delta \Delta \mathrm{Cq}}$ method (21). The primer sequences were as follows: $\beta$-actin forward, 5'-AGAGCTACGAGCTGC CTGAC-3' and reverse, 5'-AGCACTGTGTTGGCGTAC AG-3'; miR-150 forward, 5'-GGGTCTCCCAACCCTTGTA-3' and reverse, 5'-CAGTGCGTGTCGTGGAGT-3' (22); STAT1 forward, 5'-GTGAAGTTGAGAGATGTGAATGAG-3' and reverse, 5'-GATCACCACAACGGGCAGA-3' and U6 forward, 5'-AACGCTTCACGAATTTGCGT-3' and reverse, 5'-CTC GCTTCGGCAGCACA-3'.

Cell transfection. STAT1 overexpression vector was obtained by cloning the sequences of STAT1 (Shanghai GenePharma Co., Ltd.) into pcDNA3.1 (Invitrogen; Thermo Fisher Scientific, Inc.) and termed pcDNA3.1-STAT1 (STAT1). Before transfection, THP- 1 cells $\left(4 \times 10^{5}\right.$ cells per well) were seeded into 12-well plate. After incubation for $24 \mathrm{~h}, 0.2 \mu \mathrm{g}$ of STAT1 overexpression vector (STAT1) and the control pcDNA were transfected into THP-1 cells using $0.5 \mu \mathrm{l}$ of Lipofectamine 3000 reagent (Invitrogen; Thermo Fisher Scientific, Inc.). Furthermore, the oligonucleotide sequences were as follows: miR-150 mimic (5'-UCUCCCAACCCUUGU ACCAGUG-3') and negative control (miR-NC: 5'-GCCUCC GUACCGAUCCUACUUA-3'); miR-150 inhibitor (5'-CAC UGGUACAAGGGUUGGGAGA-3') and the negative control (anti-miR-NC: 5'-GGACAGGAUGGUCGAAACUGGU-3'); and small interfering RNA for STAT1 (si-STAT1: 5'-CCG GCTGGAAGATTTACAAGATGAACTCGAGTTCATCTT GTAAATCTTCCAGTTTTTG-3') and the negative control (si-NC: 5'-CCGGTTCTCCGAACGTGTCACGTTTCAAGA GAACGTGACACGTTCGGAGAATTTTTG-3'). These were purchased from Guangzhou RiboBio Co., Ltd. THP-1 cells were transfected with $0.5 \mu \mathrm{g}$ of the aforementioned oligonucleotides using $0.6 \mu 1$ of Lipofectamine 3000 (Invitrogen; Thermo Fisher Scientific, Inc.). After 24 h, THP-1 cells treated with $1 \mu \mathrm{g} / \mathrm{ml}$ LPS and untreated cells were incubated for a further $24 \mathrm{~h}$ at $37^{\circ} \mathrm{C}$ prior to further experimentation.

ELISA. THP-1 cells ( $2 \times 10^{5}$ cells/well) were grown in 12-well plates, and supernatants were collected by centrifuging at $4,000 \mathrm{x} \mathrm{g}$ for $10 \mathrm{~min}$ at room temperature. ELISA assay kits for IL-1 $\beta$ (cat. no. 437004), IL-6 (cat. no. 430501) and TNF- $\alpha$ (cat. no. 430201) were obtained from Biolegend, Inc. The levels of these cytokines were measured using their respective ELISA kits, according to the manufacturer's protocol.

Western blotting. Total proteins were isolated from THP-1 cells using RIPA buffer (Pierce; Thermo Fisher Scientific, Inc.). In total, $20 \mu \mathrm{g}$ proteins were separated by $10 \%$ SDS-PAGE and subsequently transferred onto PVDF membranes (EMD Millipore). After blocking with 5\% dried skimmed milk at room temperature for $2 \mathrm{~h}$, the membranes were incubated with anti-STAT1 (1:1,000; cat. no. sc-464, Santa Cruz Biotechnology Inc.) or anti- $\beta$-actin (1:5,000; cat. no. sc-47778, Santa Cruz Biotechnology Inc.) primary 

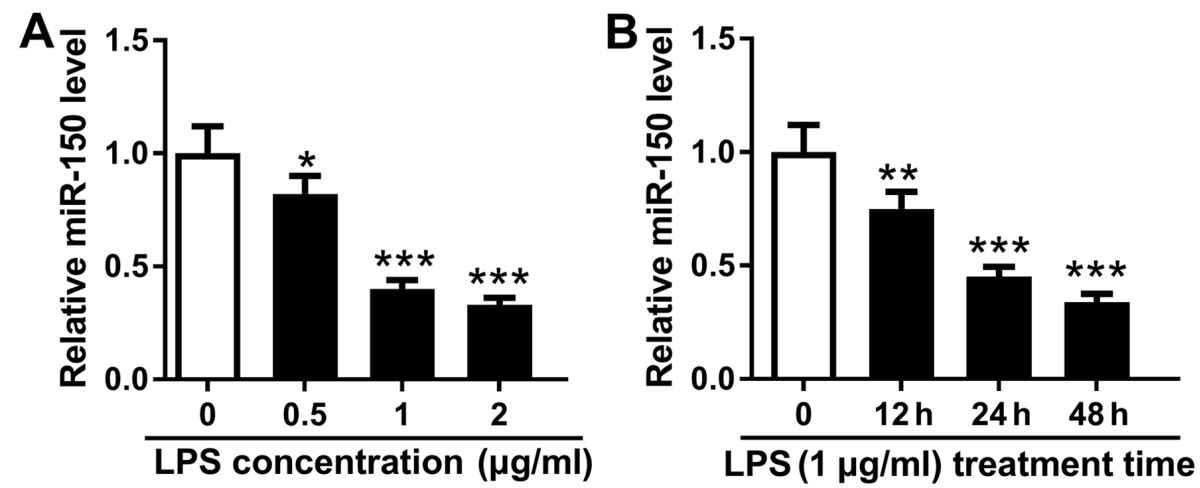

Figure 1. miR-150 expression is downregulated by LPS treatment in THP-1 cells. (A) miR-150 expression was measured in THP-1 cells treated with $0,0.5,1$ and $2 \mu \mathrm{g} / \mathrm{ml}$ LPS for $48 \mathrm{~h}$. (B) miR-150 expression was measured in THP- 1 cells treated with $1 \mu \mathrm{g} / \mathrm{ml} \mathrm{LPS}$ for $0,12,24$ and $48 \mathrm{~h}$. ${ }^{*} \mathrm{P}<0.05,{ }^{* *} \mathrm{P}<0.01$ and **** $\mathrm{P}<0.001$ vs. $0 \mu \mathrm{g} / \mathrm{ml}$ or $0 \mathrm{~h}$. LPS, lipopolysaccaharide; miR, microRNA.

antibodies overnight at $4^{\circ} \mathrm{C}$. After washing in TBS supplemented with $1.5 \%$ Tween-20, the membranes were incubated with horseradish peroxidase-conjugated secondary antibodies (1:1,000, cat. no. sc-516102, Santa Cruz Biotechnology Inc.) at room temperature for $1.5 \mathrm{~h}$. The blots were visualized using the ECL detection kit (Thermo Fisher Scientific, Inc.) and imaged using the ChemiDoc XRS System (Bio-Rad Laboratories, Inc.). Protein bands were analyzed by ImageJ v1.8.0 software (National Institutes of Health).

Dual-luciferase reporter assay. StarBase v2.0 (http://starbase.sysu.edu.cn/starbase2/) (23) predicted that STAT1 was a target gene of miR-150. Based on these prediction results, wild-type (WT) or mutant-type (with a mutation in the region of the predicted miR-150 binding site) STAT1 3'UTR sequence was amplified from DNA prepared from THP-1 cells using PCR. Then, these wild-type (WT) or mutant (MUT) 3'-unstranslated regions (3'-UTR) of STAT1 (STAT1-WT1, STAT1-MUT1, STAT1-WT2 or STAT1-MUT2) were synthesized and cloned into the pmirGLO vector (Promega Corporation). The vectors were then co-transfected into $293 \mathrm{~T}$ cells alongside the miR-150 mimic or corresponding negative control (miR-NC). DNA sequencing was used to detect the reporters. Then, $400 \mathrm{ng}$ of the constructed plasmids, $50 \mathrm{ng}$ of renilla luciferase reporter plasmid (pRL-TK) and $50 \mathrm{nM}$ of miR-NC or miR-150 were transfected into THP-1 cells using Lipofectamine 3000 (Invitrogen; Thermo Fisher Scientific, Inc.). Relative luciferase activities were measured using the Dual-Luciferase ${ }^{\circledR}$ Reporter Assay kit, according to manufacturer's protocols (Promega Corporation), $48 \mathrm{~h}$ after transfection. Renilla luciferase activity was regarded as the internal control for the normalization of firefly luciferase activity.

RNA immunoprecipitation (RIP) assay. THP-1 cells were transfected with either miR-NC or miR-150 mimics, which were used for RIP assays $48 \mathrm{~h}$ following transfection. RIP assay was performed using the Magna RIP ${ }^{\mathrm{TM}}$ RNA-Binding Protein Immunoprecipitation kit (EMD Millipore) according to manufacturer's protocols. $2 \times 10^{5}$ THP-1 cells were lysed by RIPA buffer. The samples $(200 \mu 1)$ were incubated with $5 \mu \mathrm{g}$ anti-Ago2 antibody (cat. no. 04-642, EMD Millipore) or negative control IgG (cat. no. AC111J, EMD Millipore).
Magnetic beads conjugated to protein A/G were then used to pull down the Ago2-Ab complexes. Then, these complexes were then digested, following which the RNA sequences were isolated for RT-qPCR.

Statistical analysis. Data were presented as the means \pm standard deviation. Every assay was repeated independently at least three times. Unpaired student's t-test and one-way ANOVA followed by Tukey's test were applied to assess the data between two groups and among multiple groups, respectively. The results were analyzed using the GraphPad Prism 7.0 software (GraphPad Software, Inc.). $\mathrm{P}<0.05$ was considered to indicate a statistically significant difference.

\section{Results}

miR-150 expression is downregulated in THP-1 cells following LPS treatment. LPS was first used to treat THP-1 cells to mimic sepsis in vitro. THP-1 cells were first treated with $0,0.5,1$ and $2 \mu \mathrm{g} / \mathrm{ml}$ LPS for $48 \mathrm{~h}$, where it was found that miR-150 expression reduced in a dose-dependent manner (Fig. 1A). To optimize treatment time, a dose of $1 \mu \mathrm{g} / \mathrm{ml}$ LPS was used to treat THP-1 cells for $0,12,24$ and $48 \mathrm{~h}$. The expression of miR-150 was found to be downregulated by LPS treatment in a time-dependent manner from 0 to $48 \mathrm{~h}$ (Fig. 1B). A dose of $1 \mu \mathrm{g} / \mathrm{ml}$ LPS and treatment time of $24 \mathrm{~h}$ was determined to be has the optimal treatment strategy for subsequent experiments. These data indicate that miR-150 expression in THP-1 cells was reduced by LPS treatment in dose- and time-dependent manners.

miR-150 negatively regulates the secretion of inflammatory factors in LPS-treated THP-1 cells. Sepsis is an inflammatory syndrome that is typically characterized by the secretion of cytokines including IL-1, IL- 6 and TNF- $\alpha(24,25)$. To investigate the role of miR-150 in sepsis, $\mathrm{miR}-150$ mimics were transfected into THP-1 cells for $24 \mathrm{~h}$ before treatment with $1 \mu \mathrm{g} / \mathrm{ml}$ LPS for a further $24 \mathrm{~h}$. Transfection efficiency of miR-150 mimics and miR-150 inhibitors into THP-1 cells were first confirmed in comparison with their respective negative controls (Fig. S1A and B), following which cytokine secretion into the cell supernatant was measured by ELISA after LPS challenge. The levels of IL-1 $\beta$, IL- 6 and TNF- $\alpha$ secretion were 
A

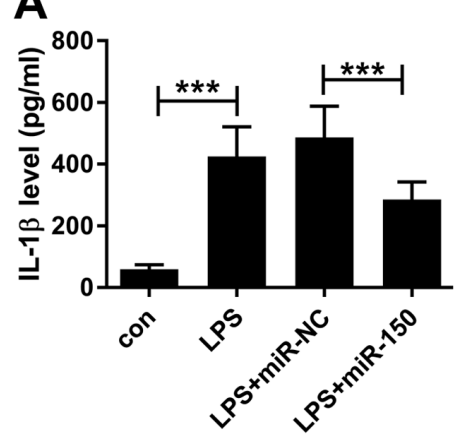

D

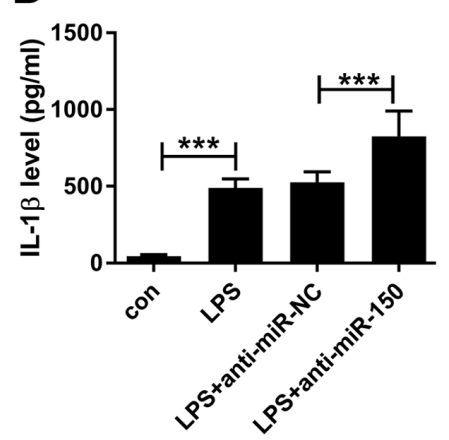

B

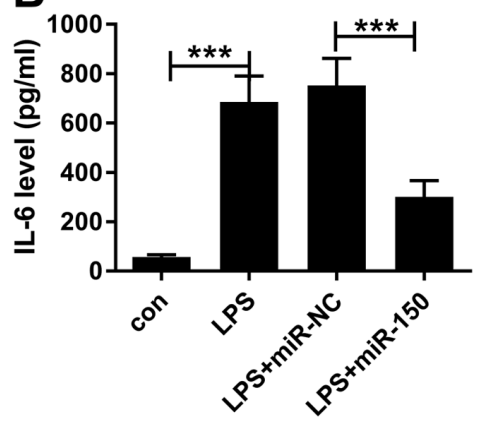

E

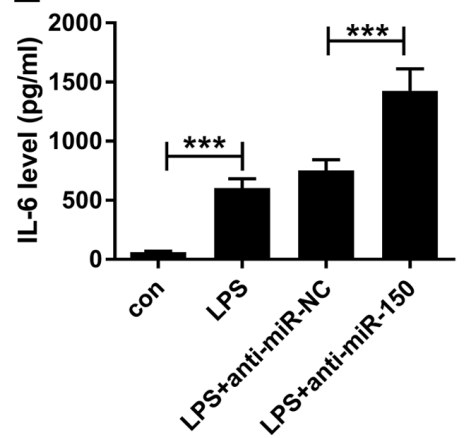

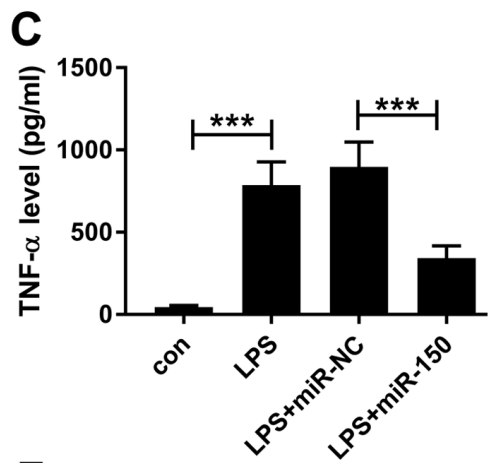

$\mathbf{F}$

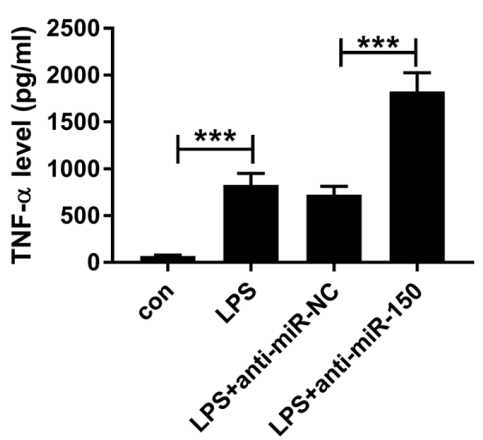

Figure 2. miR-150 regulate the secretion of inflammatory cytokines in LPS-treated THP-1 cells. THP-1 cells transfected with miR-150 mimics were treated with $1 \mu \mathrm{g} / \mathrm{ml}$ LPS for $24 \mathrm{~h}$, following which (A) IL-1 $\beta$, (B) IL- 6 and (C) TNF- $\alpha$ levels in the cell supernatant were measured by ELISA. THP-1 cells transfected with the miR-150 inhibitor were treated with $1 \mu \mathrm{g} / \mathrm{ml}$ LPS for $24 \mathrm{~h}$, following which (D) IL-1 $\beta$ (E) IL-6 and (F) TNF- $\alpha$ levels in the cell supernatant were measured by ELISA. ${ }^{* * *} \mathrm{P}<0.001$. miR, microRNA, LPS, lipopolysaccharide; IL, interleukin; TNF- $\alpha$, tumor necrosis factor- $\alpha$; miR-NC, negative control; anti-miR-NC, miR inhibitor negative control.

A

Target site 1: chr2:191847120-191847127[-] of STAT1 3' UTR

STAT1-WT1

$\operatorname{miR}-150$

STAT1-MUT2
5'... accagcugaacauUGGUAAGAC...3'
Target site 2: chr2:191834997-191835018[-] of STAT1 3' UTR

STAT1-WT2
miR-150

STAT1-MUT2

\section{5'... aacgguaaauuucugUGGGAGA...3' \\ | || ||| \\ 3' gugaccauguuccaACCCUCU $5^{\prime}$}

B

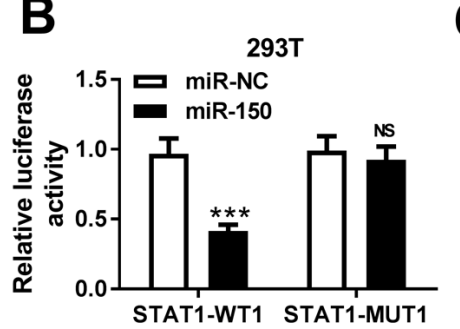

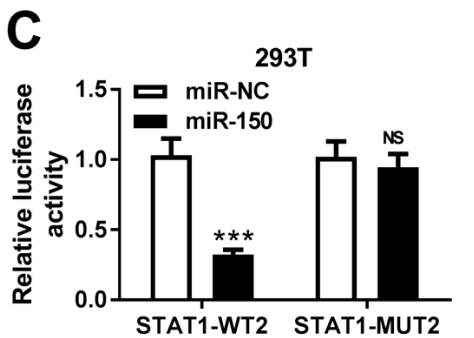
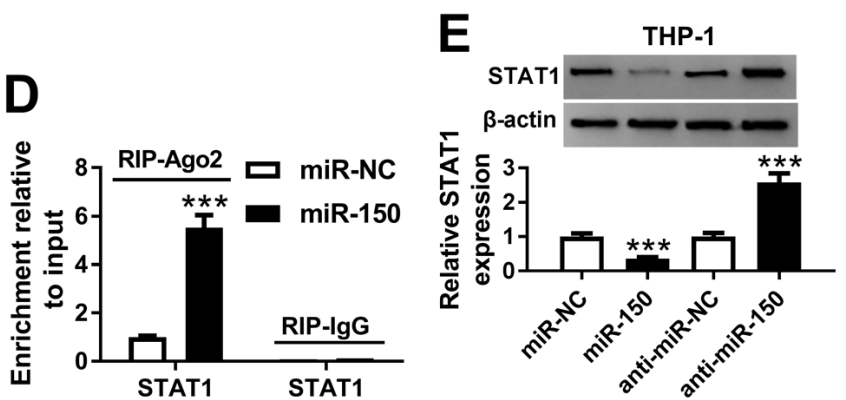

Figure 3. STAT1 is a direct target of miR-150. (A) Two complementary miR-150 binding sites on the 3'-UTR of STAT1 as predicted using the Starbase 2.0 software. (B) Overexpression of miR-150 reduced the luciferase activity of STAT1-WT1, but not that of STAT1-MUT1 in 293T cells. (C) Overexpression of miR-150 reduced the luciferase activity of STAT1-WT2 in 293T cells, but not that of STAT1-MUT2 in 293T cells. (D) Anti-Ago2 RIP assays were performed in THP-1 cells transfected with the miR-150 mimic or miR mimic NC. STAT1 mRNA levels in the precipitates were measured by reverse transcriptionquantitative PCR. (E) Protein expression of STAT1 was measured by western blotting in THP-1 cells following transfection with miR-mimic NC, miR-150 mimic, miR-inhibitor NC or miR-150 inhibitor. ${ }^{* * *} \mathrm{P}<0.001$. miR, microRNA; 3'UTR, 3'untranslated region; WT, wild-type; MUT, mutant; Ago2, protein argonaute 2; miR-NC, miR mimic negative control; anti-miR-NC, miR inhibitor negative control; RIP, RNA immunoprecipitation assay.

revealed to be significantly higher in the media of THP-1 cells treated with LPS compared with control THP-1 cells (Fig. 2). In the presence of LPS, miR-150 overexpression in THP-1 cells resulted in significant reductions in IL-1 $\beta$, IL-6 and TNF- $\alpha$ secretion compared with THP-1 cells transfected with miR-NC (Fig. 2A-C). By contrast, transfection of THP-1 cells with the miR-150 inhibitor lead to significantly higher IL-1 $\beta$, IL-6 and TNF- $\alpha$ secretion compared with cells transfected with the 

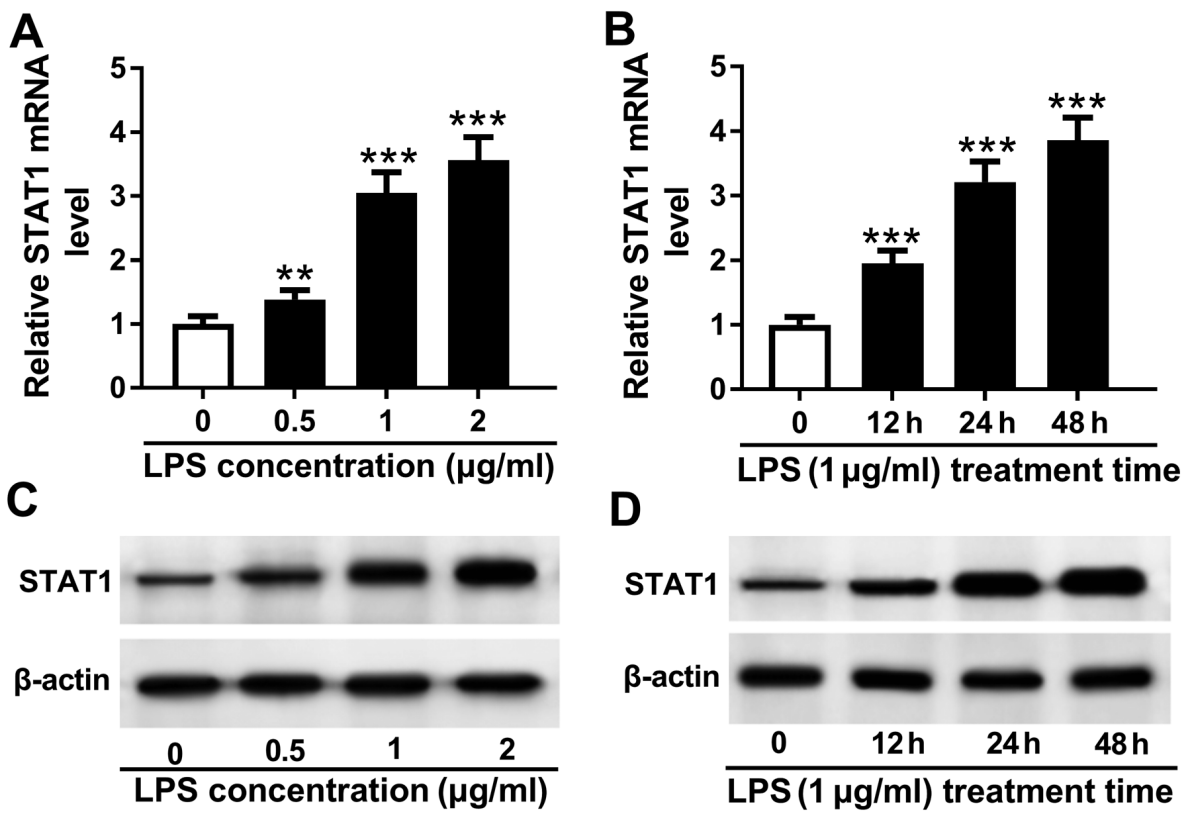

Figure 4. STAT1 expression is upregulated by LPS treatment in THP-1 cells. (A) THP-1 cells were treated with $0,0.5,1$ and $2 \mu \mathrm{g} / \mathrm{ml}$ LPS for $48 \mathrm{~h}$, following which STAT1 mRNA expression was measured by reverse transcription-quantitative PCR. (B) THP-1 cells were treated with $1 \mu \mathrm{g} / \mathrm{ml} \mathrm{LPS} \mathrm{for} 0,12,24$ and $48 \mathrm{~h}$, following which STAT1 mRNA expression was measured by reverse transcription-quantitative PCR. (C) THP-1 cells were treated with $0,0.5,1$ and $2 \mu \mathrm{g} / \mathrm{ml} \mathrm{LPS}$ for $48 \mathrm{~h}$, following which STAT1 protein expression was measured by western blotting. (D) THP-1 cells were treated with $1 \mu \mathrm{g} / \mathrm{ml} \mathrm{LPS} \mathrm{for} 0,12,24 \mathrm{and} 48 \mathrm{~h}$, following which STAT1 protein expression was measured by western blotting. Significant differences between groups were shown as ${ }^{* *} \mathrm{P}<0.01$ and ${ }^{* * * *} \mathrm{P}<0.001$ vs. $0 \mu \mathrm{g} / \mathrm{ml}$. LPS, lipopolysaccharide.

corresponding miR inhibitor negative control (Fig. 2D-F). These findings suggest that in THP-1 cells, LPS can stimulate the secretion of IL- $1 \beta$, IL- 6 and TNF- $\alpha$ in a manner that can be reversed by miR-150 overexpression but enhanced by transfection with the miR-150 inhibitor. Therefore, miR-150 may function as a negative regulator of the macrophage-mediated inflammatory response by suppressing the production of pro-inflammatory cytokines IL-1 $\beta$, IL-6 and TNF- $\alpha$.

STAT1 is a target of miR-150. A number of studies have previously demonstrated miRNA to be involved in sepsis by regulating the transcription of a number of genes downstream $(26,27)$. Therefore, the potential downstream targets of miR-150 were investigated using Starbase2.0 software. It was found that the 3'UTR of STAT1 shared two complementary binding sites with miR-150 (Fig. 3A). To verify the predicted result, dual-luciferase reporter assay was performed in $293 \mathrm{~T}$ cells. Co-transfection with the miR-150 mimic significantly inhibited the luciferase activities of STAT1-WT plasmids in 293T cells but did not affect those of STAT1-MUT plasmids (Fig. 3B and C). In addition, overexpression of miR-150 significantly increased the association between Ago2 and STAT1 in THP-1 cells compared with cells transfected with the miR mimic control, supporting the notion of a direct interaction between STAT1 and miR-150 (Fig. 3D). miR-150 overexpression significantly reduced STAT1 protein expression in THP-1 cells, whilst transfection with the miR-150 inhibitor significantly increased STAT1 expression (Fig. 3E). In conclusion, these results suggest that STAT1 is a downstream target of miR-150.

STAT1 expression is upregulated in LPS-treated THP-1 cells. To investigate the relationship between STAT1 and sepsis,
THP- 1 cells were stimulated with $0,0.5,1$ and $2 \mu \mathrm{g} / \mathrm{ml}$ LPS for $24 \mathrm{~h}$. LPS treatment increased STAT1 mRNA expression in a dose-dependent manner (Fig. 4A). In addition, stimulation with $1 \mu \mathrm{g} / \mathrm{ml}$ LPS upregulated the expression of STAT1 mRNA in a time-dependent manner from 0 to $48 \mathrm{~h}$ (Fig. 4B). This was subsequently confirmed on a protein level, which exhibited a similar trend compared with the data obtained using RT-qPCR (Fig. 4C and D). Collectively, these observations suggest that STAT1 expression is upregulated by LPS treatment in THP-1 cells.

miR-150 is involved in LPS-induced inflammatory cytokine secretion by regulating STAT1. miR-150 overexpression inhibited the secretion of inflammatory cytokines induced by LPS whilst transfection with the miR-150 inhibitor promoted secretion as aforementioned. To investigate whether STAT1 is involved in this inflammatory process and explore the functional relationship between miR-150 and STAT1, THP-1 cells were treated with LPS following co-transfection with both miR-150 mimics and plasmids encoding STAT1. Western blot analysis data showed that transfection with the pcDNA-STAT1 plasmid significantly increased STAT1 expression in THP-1 cells compared with cells transfected with the blank plasmid (Fig. S1C). In the presence of LPS and miR-150 overexpression, the levels of IL-1 $\beta$, IL- 6 and TNF- $\alpha$ secretion were revealed to be significantly increased following transfection with the pcDNA-STAT1 plasmid compared with those following transfection with the blank pcDNA plasmid (Fig. 5A-C). Following confirmation that transfection of THP-1 cells with the si-STAT1 significantly reduced the expression of STAT1 compared with cells transfected with the (Fig. S1D). STAT1 knockdown was found to significantly suppress IL-1 $\beta$, IL-6 

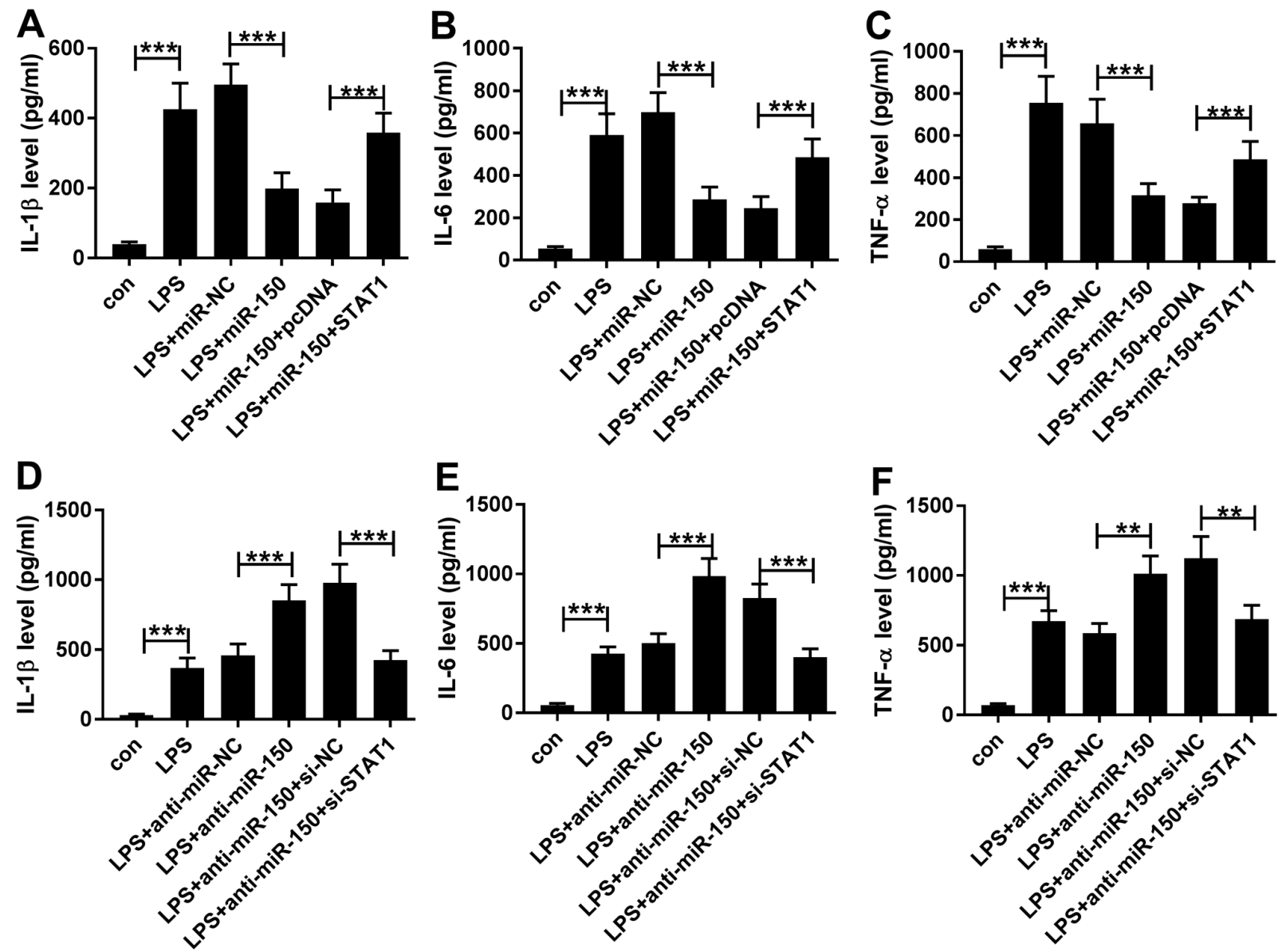

Figure 5. miR-150 regulates the secretion of inflammatory cytokines by modulating STAT1 expression. (A-C) THP-1 cells were first transfected with either miR-NC or miR-150 mimics alone, or co-transfected with miR-NC or miR-150 mimics and pcDNA or pcDNA-STAT1 before being treated with $1 \mu \mathrm{g} / \mathrm{ml}$ LPS for $24 \mathrm{~h}$. THP-1 cells in the con and LPS groups were not transfected whilst cells in the con group were not treated with LPS. (A) IL-1 $\beta$, (B) IL-6 and (C) and TNF- $\alpha$ secretion into the media supernatant by THP-1 cells were measured by ELISA. (D-F) THP-1 cells were first transfected with either miR inhibitor NC or miR-150 inhibitor alone, or co-transfected with miR inhibitor NC or miR-150 inhibitor and pcDNA or pcDNA-STAT1 before being treated with $1 \mu \mathrm{g} / \mathrm{ml}$ LPS for $24 \mathrm{~h}$. THP-1 cells in the con and LPS groups were not transfected whilst cells in the con group were not treated with LPS. (D) IL-1 $\beta$, (E) IL-6 and (F) and TNF- $\alpha$ secretion into the media supernatant by THP-1 cells were measured by ELISA. ${ }^{* *} \mathrm{P}<0.01$ and ${ }^{* * *} \mathrm{P}<0.001$. miR, microRNA; LPS, lipopolysaccharide; miR-NC, miR mimic negative control; anti-miR-NC, miR inhibitor control; IL, interleukin; TNF- $\alpha$, tumor necrosis factor- $\alpha$; si, small interfering RNA; si-NC, si-negative control.

and TNF- $\alpha$ secretion compared with corresponding siRNA control in the presence of LPS and miR-150 overexpression (Fig. 5D-F). These results suggest that miR-150 modulated the inflammatory response following LPS exposure by regulating STAT1 expression in THP-1 cells.

\section{Discussion}

The STAT family of proteins are major downstream signaling proteins of growth factors and cytokines in mammalian cells (28). STATs serve important roles in regulating immune cell homeostasis, differentiation and function (29). Significant progress has been made over the last number of decades in the characterization of the JAK/STAT signaling cascade, including the identification of multiple STATs and associated regulatory proteins (30). Seven STAT proteins, including STAT1, STAT2, STAT3, STAT4, STAT6 and the STAT5a and STAT5b isoforms, have been identified in mammals, each with their own distinct established roles in the immune response (31). The predominant mode of STAT regulation is by phosphorylation, mainly by JAKs (32). STAT1 and STAT2 have been demonstrated to promote gene transcription downstream of interferon stimulation and anti-viral immunity (33), whereas STAT3 responds to factors including IL-6, IL-10 and vascular endothelial growth factor and has been previously associated with tumorigenesis, $\mathrm{T}$ helper cell (Th)17 and regulatory $\mathrm{T}$ cell development (34). STAT4 and STAT6 regulate Th1 and Th2 cell differentiation in response to IL-12 and IL-4/13 (35), respectively. As a result, stringent regulation of cellular STAT activity is of great importance due to their involvement in such a wide variety of physiological processes.

Sepsis is a systemic inflammatory response and remains to be a major cause of morbidity and mortality in patients that are critically ill (36), which is associated with tissue damage and organ failure (37). In particular, following the failure of one organ as a result of sepsis, others typically follow, in a process known as organ failure amplification (38). Therefore, clinical intervention of sepsis remains to be a great challenge. The pathophysiological process of sepsis involves a series of complex reactions, one of which is the activation of numerous inflammatory responses. A number of studies have demonstrated that the inflammatory response can be regulated via the 
JAK/STAT pathway. Chitnis et al (35) found that STAT4 and STAT6 genes exerted a vital role in regulating the autoimmune response in experimental autoimmune encephalomyelitis. Wang et al (11) demonstrated that miR-30a could inhibit MD-2 expression by targeting STAT1 in human monocytes of sepsis, whilst Song et al (39) revealed that IL-4-induced activation of the STAT6 signaling pathway contributes to the suppression of cell-mediated immunity and death in sepsis.

miRNAs are endogenous, non-coding single-stranded RNAs that are typically 19-23 nucleotides in length (40). They have been previously demonstrated to serve an important role in sepsis. Wu et al (41) previously showed that miR-23b serves a significant role in the pathogenesis and progression of sepsis by inhibiting the expression of inflammatory factors. Gao and Dong (42) demonstrated that miR-146 regulates the expression of inflammatory cytokines in vascular endothelial cells during sepsis. Wang et al (43) previously found miR-27a expression to be upregulated, which promotes inflammatory responses in sepsis, whereas another study previously demonstrated elevated miR-15a/16 levels in the serum of patients with neonatal sepsis, which inhibited the LPS-induced inflammatory pathway (44). These aforementioned studies suggest that miRNAs serve key regulatory roles in the inflammatory response during sepsis. Although miR-150 has been previously revealed to serve key roles in diabetes and other autoimmune diseases (45), the role of this miRNA in sepsis remains unclear. In the present study, it was confirmed that miR-150 expression was downregulated in LPS-stimulated THP-1 cells, consistent with the reduced miR-150 expression observed in patients with sepsis (46). Results from the present study also demonstrated that miR-150 functioned as a negative regulator of the macrophage inflammatory response by suppressing the production of pro-inflammatory cytokines IL-1 $\beta$, IL- 6 and TNF- $\alpha$. miR-150 was found to share two complementary binding sites with the 3'-UTR of STAT1 by Bioinformatics analysis, which was confirmed by dual-luciferase reporter assay. In accordance with this finding, the expression levels of STAT1 in THP-1 cells was measured in the present study, which revealed that STAT1 was upregulated in LPS-treated THP-1 cells. It was also found that the secretion of IL-1 $\beta$, IL- 6 and TNF- $\alpha$ were increased by STAT1 overexpression, whilst STAT1 knockdown resulted in the opposite effect.

In conclusion, the present study demonstrated that miR-150 inhibits the LPS-induced THP-1 inflammatory response and revealed a direct regulatory relationship between miR-150 and STAT1 in LPS-induced THP-1 cells. These results highlight the association of miRNAs with sepsis and specifically suggest that miR-150 may serve as a potential target for the development of future treatment of sepsis.

\section{Acknowledgements}

Not applicable.

\section{Funding}

The present study was supported by the Project of Clinical Outstanding Clinical Discipline Construction in Shanghai Pudong New Area (No. PWYgy2018-07). Project of Shanghai
Municipality Key Medical Specialties Construction (No. ZK2019C08). Key Clinical Medical Specialties Project in Shanghai Pudong New Area No. PWZzk2017-22). Leading Talent Training in Shanghai Pudong New Area Health System No. PWR12018-08).

\section{Availability of data and materials}

The datasets used and/or analyzed during the current study are available from the corresponding author on reasonable request.

\section{Authors' contributions}

SC and JW conceived and designed the study, collected the clinical data and drafted the manuscript. $\mathrm{HZ}$ and JS performed the cellular experiments. LZ and LQ interpreted the data and revised the manuscript. SC and JW confirm the authenticity of all the raw data. All authors read and approved the final manuscript.

\section{Ethics approval and consent to participate}

Not applicable.

\section{Patient consent for publication}

Not applicable.

\section{Competing interests}

The authors declare that they have no competing interests.

\section{References}

1. Csoka B, Nemeth ZH, Toro G, Idzko M, Zech A, Koscso B, Spolarics Z, Antonioli L, Cseri K, Erdelyi K, et al: Extracellular ATP protects against sepsis through macrophage $\mathrm{P} 2 \mathrm{X} 7$ purinergic receptors by enhancing intracellular bacterial killing. FASEB J 29: 3626-3637, 2015.

2. Rudd KE, Johnson SC, Agesa KM, Shackelford KA, Tsoi D, Kievlan DR, Colombara DV, Ikuta KS, Kissoon N, Finfer S, et al: Global, regional, and national sepsis incidence and mortality, 1990-2017: Analysis for the Global Burden of Disease Study. Lancet 395: 200-211, 2020.

3. Stearns-Kurosawa DJ, Osuchowski MF, Valentine C, Kurosawa S and Remick DG: The pathogenesis of sepsis. Annu Rev Pathol 6: 19-48, 2011.

4. Yao YM, Luan YY, Zhang QH and Sheng ZY: Pathophysiological aspects of sepsis: An overview. Methods Mol Biol 1237: 5-15, 2015.

5. He Q, Zhao L, Liu Y, Liu X, Zheng J, Yu H, Cai H, Ma J, Liu L, Wang P, et al: circ-SHKBP1 regulates the angiogenesis of U87 Glioma-exposed endothelial cells through miR-544a/FOXP1 and miR-379/FOXP2 pathways. Mol Ther Nucleic Acids 10: 331-348, 2018.

6. Owens TW, Taylor RJ, Pahil KS, Bertani BR, Ruiz N, Kruse AC and Kahne D: Structural basis of unidirectional export of lipopolysaccharide to the cell surface. Nature 567: 550-553, 2019.

7. Li Y, Orlando BJ and Liao M: Structural basis of lipopolysaccharide extraction by the LptB2FGC complex. Nature 567: 486-490, 2019.

8. Beutler B and Rietschel ET: Innate immune sensing and its roots: The story of endotoxin. Nat Rev Immunol 3: 169-176, 2003.

9. Wang Y, Zhang MX, Meng X, Liu FQ, Yu GS, Zhang C, Sun T, Wang XP, Li L, Wang YY, et al: Atorvastatin suppresses LPS-induced rapid upregulation of Toll-like receptor 4 and its signaling pathway in endothelial cells. Am J Physiol Heart Circ Physiol 300: H1743-H1752, 2011. 
10. Ma Y, Liu Y, Hou H, Yao Y and Meng H: miR-150 predicts survival in patients with sepsis and inhibits LPS-induced inflammatory factors and apoptosis by targeting NF-kappaB1 in human umbilical vein endothelial cells. Biochem Biophys Res Commun 500: 828-837, 2018.

11. Wang Y, Li T, Wu B, Liu H, Luo J, Feng D and Shi Y: STAT1 regulates MD-2 expression in monocytes of sepsis via miR-30a. Inflammation 37: 1903-1911, 2014.

12. Lv X, Zhang Y, Cui Y, Ren Y, Li R and Rong Q: Inhibition of microRNA155 relieves sepsisinduced liver injury through inactivating the JAK/STAT pathway. Mol Med Rep 12: 6013-6018, 2015.

13. Seven M, Karatas OF, Duz MB and Ozen M: The role of miRNAs in cancer: From pathogenesis to therapeutic implications. Future Oncol 10: 1027-1048, 2014

14. van Rooij E and Olson EN: MicroRNA therapeutics for cardiovascular disease: Opportunities and obstacles. Nat Rev Drug Discov 11: 860-872, 2012.

15. Liu YP, Gruber J, Haasnoot J, Konstantinova P and Berkhout B: RNAi-mediated inhibition of HIV-1 by targeting partially complementary viral sequences. Nucleic Acids Res 37: 6194-6204, 2009.

16. Li M, Chen H, Chen L, Chen Y, Liu X and Mo D: miR-709 modulates LPS-induced inflammatory response through targeting GSK-3 $\beta$. Int Immunopharmacol 36: 333-338, 2016.

17. Alipoor SD, Mortaz E, Tabarsi P, Marjani M, Varahram M, Folkerts G, Garssen J and Adcock IM: miR-1224 expression is increased in human macrophages after infection with bacillus Calmette-Guerin (BCG). Iran J Allergy Asthma Immunol 17: 250-257, 2018.

18. Guo X, Zhang Z, Zeng T, Lim YC, Wang Y, Xie X, Yang S, Huang C, Xu M, Tao L, et al: cAMP-MicroRNA-203-IFN $\gamma$ network regulates subcutaneous white fat browning and glucose tolerance. Mol Metab 28: 36-47, 2019.

19. Murphy AJ, Guyre PM and Pioli PA: Estradiol suppresses NF-kappa B activation through coordinated regulation of let-7a and miR-125b in primary human macrophages. J Immunol 184 5029-5037, 2010

20. Xu G, Zhang Z, Xing Y, Wei J, Ge Z, Liu X, Zhang Y and Huang X: MicroRNA-149 negatively regulates TLR-triggered inflammatory response in macrophages by targeting MyD88. J Cell Biochem 115: 919-927, 2014.

21. Livak KJ and Schmittgen TD: Analysis of relative gene expression data using real-time quantitative PCR and the 2(-Delta Delta C(T)) method. Methods 25: 402-408, 2001

22. Xiao C, Calado DP, Galler G, Thai TH, Patterson HC, Wang J, Rajewsky N, Bender TP and Rajewsky K: miR-150 controls B cell differentiation by targeting the transcription factor $\mathrm{c}-\mathrm{Myb}$. Cell 131: 146-159, 2007.

23. Luo JF, Xu J and Zheng JZ: Long non-coding RNA TTN-AS1 promotes cell proliferation and inhibits cell apoptosis in prostatic cancer by sponging miR-193a-5p. Eur Rev Med Pharmacol Sci 23: 7816-7825, 2019 .

24. Tsimikas S, Duff GW, Berger PB, Rogus J, Huttner K, Clopton P, Brilakis E, Kornman KS and Witztum JL: Pro-inflammatory interleukin-1 genotypes potentiate the risk of coronary artery disease and cardiovascular events mediated by oxidized phospholipids and lipoprotein(a). J Am Coll Cardiol 63: 1724-1734, 2014.

25. Chaves de Souza JA, Nogueira AV, Chaves de Souza PP, Kim YJ, Silva Lobo C, Pimentel Lopes de Oliveira GJ, Cirelli JA, Garlet GP and Rossa C Jr: SOCS3 expression correlates with severity of inflammation, expression of proinflammatory cytokines, and activation of STAT3 and p38 MAPK in LPS-induced inflammation in vivo. Mediators Inflamm 2013: 650812, 2013.

26. Sheng B, Zhao L, Zang X, Zhen J and Chen W: miR-375 ameliorates sepsis by downregulating miR-21 level via inhibiting JAK2-STAT3 signaling. Biomed Pharmacother 86: 254-261, 2017.

27. Liu F, Li Y, Jiang R, Nie C, Zeng Z, Zhao N, Huang C, Shao Q, Ding C, Qing C, et al: miR-132 inhibits lipopolysaccharide-induced inflammation in alveolar macrophages by the cholinergic anti-inflammatory pathway. Exp Lung Res 41: 261-269, 2015

28. Carlesso N, Frank DA and Griffin JD: Tyrosyl phosphorylation and DNA binding activity of signal transducers and activators of transcription (STAT) proteins in hematopoietic cell lines transformed by Bcr/Abl. J Exp Med 183: 811-820, 1996.
29. Wex T, Grungreiff K, Schutte K, Stengritt M and Reinhold D: Expression analysis of zinc transporters in resting and stimulated human peripheral blood mononuclear cells. Biomed Rep 2: 217-222, 2014

30. Marengo E, Robotti E, Cecconi D, Hamdan M, Scarpa A and Righetti PG: Identification of the regulatory proteins in human pancreatic cancers treated with Trichostatin A by 2D-PAGE maps and multivariate statistical analysis. Anal Bioanal Chem 379: 992-1003, 2004

31. Gao B, Wang H, Lafdil F and Feng D: STAT proteins-key regulators of anti-viral responses, inflammation, and tumorigenesis in the liver. J Hepatol 57: 430-441, 2012.

32. Seidel HM, Lamb P and Rosen J: Pharmaceutical intervention in the JAK/STAT signaling pathway. Oncogene 19: 2645-2656, 2000.

33. Li X, Leung S, Qureshi S, Darnell JE Jr and Stark GR: Formation of STAT1-STAT2 heterodimers and their role in the activation of IRF-1 gene transcription by interferon-alpha. J Biol Chem 271: 5790-5794, 1996

34. Li Y, Yu C, Zhu WM, Xie Y, Qi X, Li N and Li JS: Triptolide ameliorates IL-10-deficient mice colitis by mechanisms involving suppression of IL-6/STAT3 signaling pathway and down-regulation of IL-17. Mol Immunol 47: 2467-2474, 2010

35. Chitnis T, Najafian N, Benou C, Salama AD, Grusby MJ, Sayegh MH and Khoury SJ: Effect of targeted disruption of STAT4 and STAT6 on the induction of experimental autoimmune encephalomyelitis. J Clin Invest 108: 739-747, 2001.

36. Hranjec T and Sawyer RG: Management of infections in critically ill patients. Surg Infect (Larchmt) 15: 474-478, 2014.

37. Weledji EP and Ngowe MN: The challenge of intra-abdominal sepsis. Int J Surg 11: 290-295, 2013.

38. Pearse RM, Moreno RP, Bauer P, Pelosi P, Metnitz P, Spies C, Vallet B, Vincent JL, Hoeft A and Rhodes A; European Surgical Outcomes Study (EuSOS) group for the Trials groups of the European Society of Intensive Care Medicine and the European Society of Anaesthesiology: Mortality after surgery in Europe: A 7 day cohort study. Lancet 380: 1059-1065, 2012.

39. Song GY, Chung CS, Chaudry IH and Ayala A: IL-4-induced activation of the Stat6 pathway contributes to the suppression of cell-mediated immunity and death in sepsis. Surgery 128: 133-138, 2000.

40. Spiegel JC, Lorenzen JM and Thum T: Role of microRNAs in immunity and organ transplantation. Expert Rev Mol Med 13: e37, 2011

41. Wu M, Gu JT, Yi B, Tang ZZ and Tao GC: microRNA-23b regulates the expression of inflammatory factors in vascular endothelial cells during sepsis. Exp Ther Med 9: 1125-1132, 2015.

42. Gao N and Dong L: MicroRNA-146 regulates the inflammatory cytokines expression in vascular endothelial cells during sepsis. Pharmazie 72: 700-704, 2017

43. Wang Z, Ruan Z, Mao Y, Dong W, Zhang Y, Yin N and Jiang L: miR-27a is up regulated and promotes inflammatory response in sepsis. Cell Immunol 290: 190-195, 2014.

44. Wang $X$, Wang $X$, Liu X, Wang X, Xu J, Hou S, Zhang $X$ and Ding Y: miR-15a/16 are upreuglated in the serum of neonatal sepsis patients and inhibit the LPS-induced inflammatory pathway. Int J Clin Exp Med 8: 5683-5690, 2015.

45. Estrella S, Garcia-Diaz DF, Codner E, Camacho-Guillen P and Perez-Bravo F: Expression of miR-22 and miR-150 in type 1 diabetes mellitus: Possible relationship with autoimmunity and clinical characteristics. Med Clin (Barc) 147: 245-247, 2016 (In Spanish).

46. Hirschberger S, Hubner M, Strauss G, Effinger D, Bauer M, Weis S, Giamarellos-Bourboulis EJ and Kreth S: Identification of suitable controls for miRNA quantification in T-cells and whole blood cells in sepsis. Sci Rep 9: 15735, 2019.

This work is licensed under a Creative Commons Attribution-NonCommercial-NoDerivatives 4.0 International (CC BY-NC-ND 4.0) License. 